\title{
Greenhouse gas emissions associated with sustainable diets in relation to climate change and health
}

\author{
C.J. Reynolds ${ }^{1}$, J.I. Macdiarmid ${ }^{1}$, S. Whybrow ${ }^{1}$, G. Horgan ${ }^{3}$ and J. Kyle ${ }^{2}$ \\ ${ }^{1}$ Rowett Institute of Nutrition and Health, ${ }^{2}$ Institute of Applied Health Sciences, University of Aberdeen, AB25 2ZD \\ and ${ }^{3}$ Biomathematics \& Statistics Scotland, Aberdeen, AB21 9SB
}

The link between health consequences and the environmental impact of the diet has generated the debate about future dietary guidance for ensuring healthy and environmentally sustainable diets. It is generally agreed that animal products tend to have a higher environmental impact than plant-based products, however recent work has highlighted that this can depend on the functional unit of measurement for the environmental impact (e.g. greenhouse gas $(\mathrm{GHG})$ emission as $\mathrm{kgCO}_{2}$ e per unit weight $(\mathrm{g})$ or per unit of energy $\left.(\mathrm{MJ})\right)^{(1,2)}$. Different functional units for GHG emissions varies the relational magnitude of the environmental impact, meaning that different environmental impacts can be reported for the same food, potentially changing what constitutes a sustainable and healthy diet.

In terms of eating sustainable diets, it may be more realistic to consider the relative environmental impact by portion size, since the amount we eat varies by the type of food. The aim of this study was to compare the relative difference by three functional units (weight (per100 g), energy (per MJ) and portion size (g). The energy content of 88 commonly consumed foods were linked to GHG emission data $^{(3)}$. The foods were then grouped into the Eatwell plate food groups (sub-dividing plant and animal proteins).

The results showed that irrespective of the functional unit animal-based proteins, especially red meat, consistently had higher GHG emissions than the other food groups. Expressed per unit energy (MJ), fruit and vegetables were found to have higher relative emissions, due to their low energy density but considered by portion size were substantially lower. The difference between the fruit $\&$ vegetable group and animal-based proteins is illustrated in Figure 2. The relative GHG emissions differed within dairy products by portion size, due to the small portion sizes that dairy products are typically eaten in. Other groups such as starchy foods, plant-based proteins and high fat \&/or high sugar foods remained lower relative to the other food groups irrespective of the functional unit.

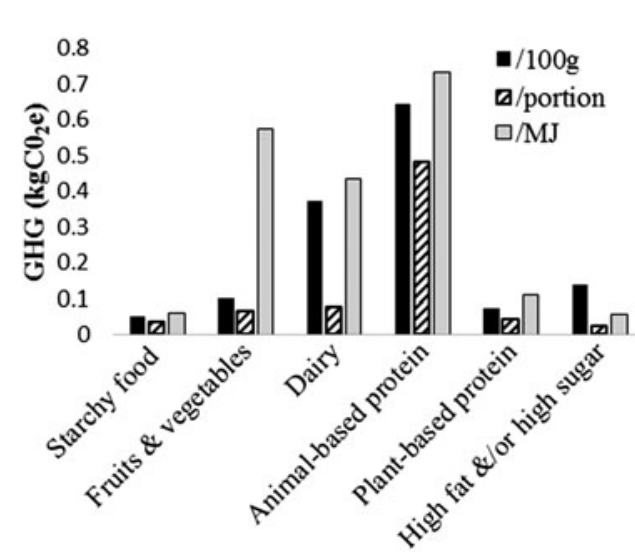

Fig. 1. The median GHG emissions by food group using three different functional units.

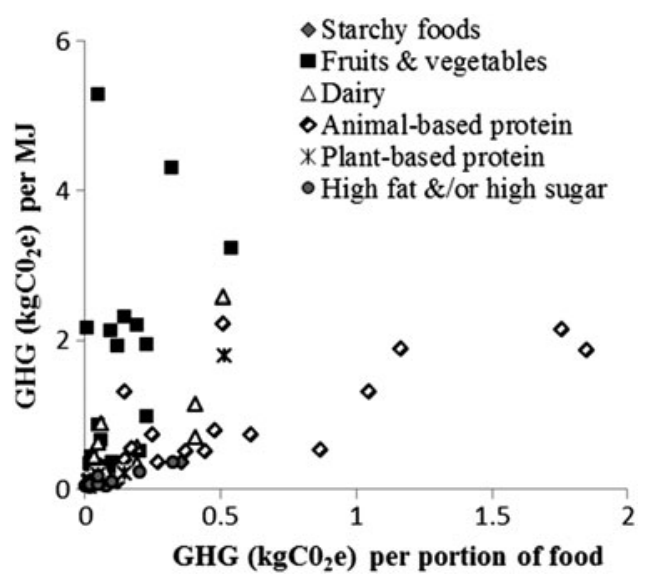

Fig. 2. GHG emissions of individual foods comparing MJ with portion size.

These results service to illustrate the complexity of combining the nutritional composition with the environmental impact of foods in order to understand sustainable diets. It highlights the importance of reporting the choice of functional units in studies for interpretation the environmental impact of the diet. However, regardless of the functional unit, animal based proteins relative to the other food groups were associated with the highest GHG emissions.

1. Masset G, Soler L-G, Vieux F, et al. (2014) Identifying sustainable foods: the relationship between environmental impact, nutritional quality, and prices of foods representative of the French diet. J Acad Nutr Diet. 114 (6), 862-9.

2. Drewnowski A, Rehm CD, Martin A, et al. (2015) Energy and nutrient density of foods in relation to their carbon footprint. Am J Clin Nutr. 101(1), 184-91.

3. Macdiarmid J, Kyle J, Horgan G. et al. (2012) Sustainable diets for the future: can we contribute to reducing greenhouse gas emissions by eating a healthy diet? Am J Clin Nutr. 93(3), 632-9. 